\title{
Para conhecer
}

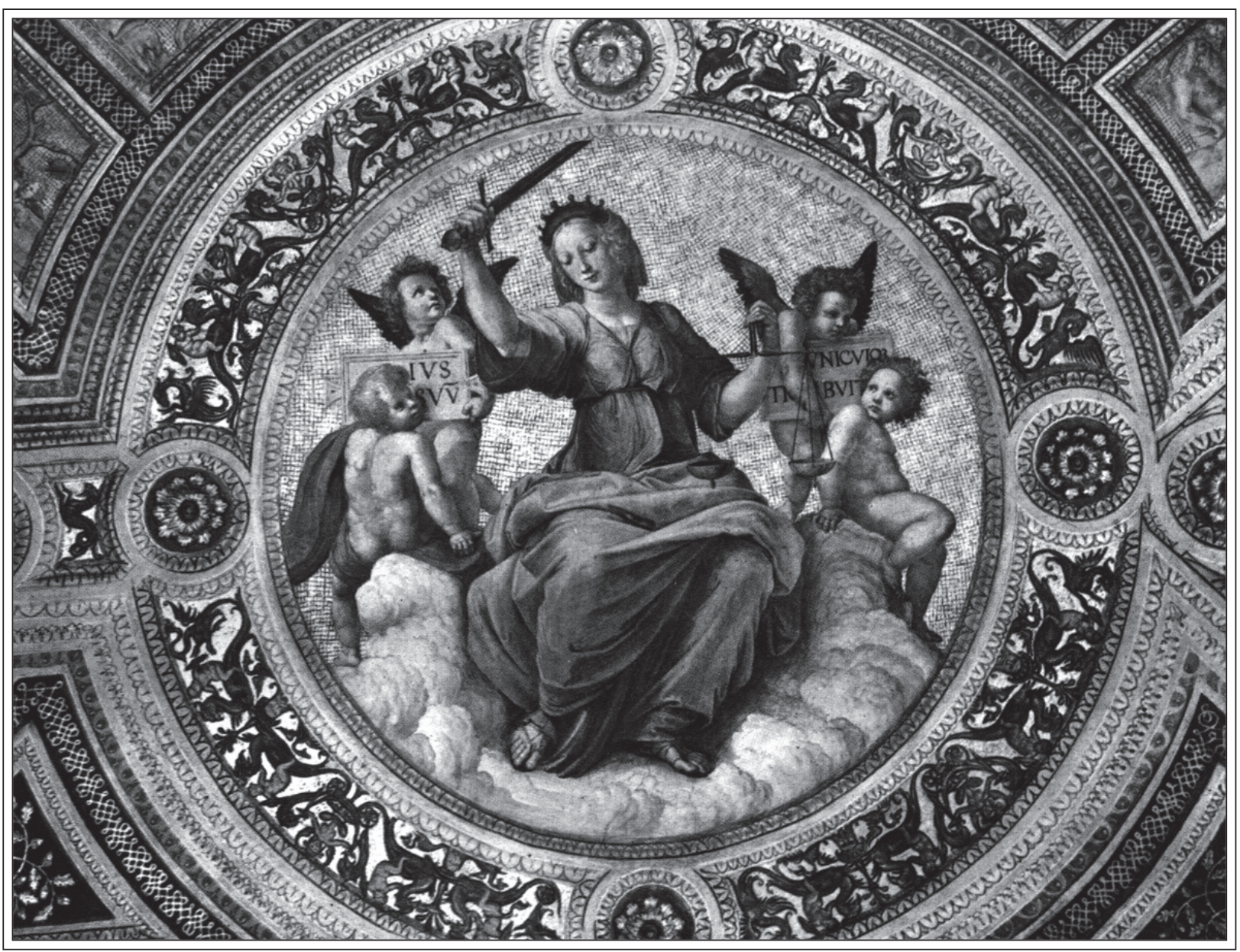

\section{os direitos humanos}

Acima, A Justiça, de Rafael Sanzio 
A história dos direitos que emerge do texto de Fábio Konder Comparato constitui expressão maior do processo de "emancipação da humanidade”, para usar a linguagem de Habermas. Trata-se de um livro que foi muito esperado por todos os que têmo privilégio de conviver e aprender com o intelectual e militante Fábio Comparato. Escrito com invulgar erudição e inteligência, não vem preencher lacuna na nossa bibliografia, mas construir um novo patamar, um espaço próprio, para a reflexão sobre os direitos humanos como instrumento de realização da dignidade das pessoas.

A leitura d'A Afirmação Histórica dos Direitos Humanos pode ser dividida em três partes. Uma introdução, em que se traçam os fundamentos históricos e, sobretudo, filosóficos dos direitos humanos. Uma parte central, em que são analisados os principais documentos relativos aos direitos humanos produzidos pela humanidade, da Magna Carta, de 1215, à Convenção sobre a Diversidade Biológica, de 1992, passando pelas Declarações Americanas e Francesa, do século XVIII, pelas Convenções de Genebra, de 1949, pelas cartas de direitos das constituições mexicana, de 1917, e alemã, de 1919, e pelos diversos instrumentos internacionais produzidos a partir da Declaração Universal de 1948, tanto no âmbito global como regional. E uma terceira parte, em que o autor se propõe a olhar, dilematicamente, e sob a perspectiva dos direitos humanos, para o futuro. Aqui, coloca todos em alerta.

O livro começa do começo, do essencial. Pergunta o autor desde quando o ser humano tem consciência de sua natureza e a partir de que momento essa consciência provoca a construção de mecanismos, chamados direitos, voltados a assegurar que a condição humana não seja degradada. Para o autor esse é o "período axial", como denominado por Karl Jaspers, que se situa entre os séculos VII e II a.C. Foi nesse período de "Zaratustra na Pérsia, Buda na Índia, Confúcio na China, Pitágoras na Grécia e o Dêutero-Isaías em Israel", somados a Homero, Maomé, Sófocles, Sócrates, Platão, os estóicos e tantos outros, que "o ser humano passa a ser considerado [...] em sua igualdade essencial, como ser dotado de liberdade e razão, não obstante as múltiplas diferenças de sexo, raça, religião ou costumes sociais. Lançam-se, assim, os fundamentos intelectuais [...] para a afirmação de direitos universais", o que somente ocorrerá mais de vinte séculos depois, com a Declaração Universal dos Direitos Humanos, de 1948, como destaca o autor.

A idéia de que as pessoas têm direitos pelo simples fato de serem humanas, no entanto, não pode ser dissociada do conceito de lei, pois esta é o "grande antídoto contra o arbítrio governamental" e o mecanismo pelo qual se estabelece igualdade onde há diferença, como expresso na citação de Eurípides, "uma vez escritas as leis o fraco e o rico gozam de um direito igual" (p. 12). A necessidade de se contar com esse poderoso instrumento voltado a organizar expectativas, racionalizar ações, igualizar status e limitar o poder do Estado, não significa que o autor se submeta à lógica positivista, pela qual autoritas non veritas facit legem.

Sem a lei escrita, geral e abstrata, as pessoas encontrar-se-iam entregues ao arbítrio dos governantes. Aceitar essa necessidade formal não impede o autor de ter uma posição reflexiva em relação à validade do direito. Mais do que eficazes, as leis para terem validade precisam ser compatíveis com parâmetros éticos, racionalmente justificáveis. Na linguagem de Kant "uma teoria empírica pura do direito" que reduza o direito ao fato social, "como a cabeça de madeira na fábula de Fedrus, pode ter uma bela aparência, mas não irá infelizmente conter cérebro" (1). É dessa armadilha que Fábio Comparato nos ajuda a fugir.

O princípio fundamental da ética kantiana, assumida por Fábio Comparato, é a de que o "ser humano e, de modo geral, todo o ser racional, existe como um fim em si mesmo, não simplesmente como um meio do qual esta ou aquela vontade possa servir-se a seu talante" (p. 20). A razão é que confere essa posição especial aos seres humanos. Para Kant, as leis naturais não cons-

\section{OSCAR VILHENA}

VIEIRA é professor de Direitos Humanos da PUCSP e de Direito Constitucional da Escola de Direito Global da SBDP e autor de, entre outros, $A$ Constituição e sua Reservo de Justica (Malheiros).

A Afirmacão Histórica dos Direitos Humanos, de Fábio Konder Comparato, São Paulo, Saraiva, 1999

Reiss, Kant Political Writtings, Cambridge, Cambridge University Press, p. 132 
tituem algo inerente à natureza, “mas construções da mente utilizadas para o propósito de entender a natureza" (2). O estabelecimento de regras éticas não deriva, assim, da experiência, mas de proposições lógicas a priori, que possam ser adotadas como lei universal. Esses imperativos categóricos, na linguagem de Kant, são juízos formais, que não estipulam o conteúdo dos direitos, mas a fórmula pela qual a razão humana pode descrever esferas recíprocas de autonomia para os indivíduos.

Essa possibilidade aberta por Kant, de vislumbrar o homem como dotado de razão prática, ou seja, como capaz de tomar decisões éticas, permite ao autor afastar-se do realismo maquiavélico e do positivismo hobbesiano. Tomando os "homens com fins em si mesmos" e obedecendo a máximas construídas livremente e que possam ser universalizáveis, estaremos construindo racionalmente a esfera ética, na qual se insere o Direito.

Fábio Konder Comparato, nesse sentido, toma os direitos como fruto da razão ética e não como mero resultado de uma conjuntura política. Como fica claro pela leitura do texto, o fundamento último dos direitos é a "consciência ética coletiva, a convicção, longa e largamente estabelecida na comunidade, de que a dignidade da condição humana exige o respeito a certos bens ou valores em qualquer circunstância, ainda que não reconhecidos no ordenamento estatal...” (p. 47). A existência de direitos, assim, não pressupõe o seu reconhecimento pelo Estado.

Nesse ponto Fábio Comparato refuta o cerne do argumento positivista, para o qual os direitos só existem se puderem ser defendidos judicialmente: “o que há, na verdade, em tal raciocínio, é a confusão entre o direito subjetivo propriamente dito, que é a pertinência de um bem da vida a alguém, e a chamada pretensão, queé modo, judicial ou extrajudicial, reconhecido pelo ordenamento jurídico, para garantir o respeito ao direito subjetivo. A ausência ou o não-exercício da pretensão não significa, de modo algum, que não haja direito subje- lançaria num posição cética, em que os direitos se confundiriam com uma mera expressão do poder. Em última instância isto significaria acatar a idéia de que os Estados totalitários não violaram direitos, pois, afinal, eles não os reconheciam. O que é logicamente plausível, mas eticamente inaceitável.

Pode-se dizer, a partir da construção teórica proposta pelo autor, que os direitos devem funcionar como razões peremptórias na conformação das condutas, sejam elas condutas públicas ou individuais. Ao classificar algo como um direito humano, este deve, prima facie, prevalecer sobre outros interesses ou valores, não por serem eventualmente reconhecidos pelo Estado, mas por serem eticamente justificáveis, como indispensáveis à realização da dignidade humana. Assim, num conflito entre diversos valores, reivindicá-los por intermédio da gramática dos direitos significa estabelecer uma prioridade desses valores guardados por direitos sobre outros que não se qualificaram eticamente para receber tal designação. Os direitos se transformam, dessa maneira, em razões que devem orientar a conduta do Estado e dos demais indivíduos. $\mathrm{Na}$ realidade, ter um direito significa ser beneficiário de um dever, como já lembrava Bentham, mesmo que o Estado não esteja disposto a reconhecer esse dever ou exigir o seu cumprimento por parte de terceiros.

Nesse esquema temos direito a integridade física em função da nossa dignidade. O não-reconhecimento pelo Estado do seu dever de não me torturar não é capaz de anular o meu direito a não ser torturado. Os direitos humanos poderiam, assim, ser compreendidos como razões peremptórias, pois eticamente fundadas, para que outras pessoas ou instituições estejam obrigadas, e, portanto, tenham deveres, em relação àquelas pessoas que reivindicam a proteção ou realização de valores e necessidades essenciais à realização da dignidade humana.

Fincadas as bases de sua teoria dos direitos humanos, Fábio Comparato passa a tratar da história política desses direitos, ou seja, o processo pelo qual os direitos, no 
sentido forte da palavra, vão sendo reconhecidos pelo ordenamento jurídico estatal ou internacional, o que amplia a sua possibilidade de eficácia. Não há aqui nenhuma contradição, pois, ao afirmar a independência dos direitos humanos de qualquer reconhecimento positivo, Fábio Comparato não nega que esse reconhecimentoé extremamente favorável à realização dos direitos humanos.

Situando o contexto histórico, político e filosófico, o autor faz uma exegese primorosa de cada texto, na melhor tradição dos jurisconsultos. A Carta Magna, de 1215, é o ponto de partida. Exemplo de pacto medieval, entre o monarca e a aristocracia, a Carta de João Sem Terra é apenas um embrião do que veio a ser a "Era das Declarações". A distinção fundamental está no fato de que o documento, antes de tudo, assegura privilégios e não direitos, ou seja, há a limitação do exercício do poder por parte do Estado, mas as esferas protegidas não são universalizáveis, nem pressupõem a igualdade entre os seus detentores. Privilégios nada mais são do que "não-direitos" no sentido contemporâneo, pois arbitrariamente distribuídos apenas a um determinado grupo, logo não extensíveis aos demais membros de uma determinada comunidade. O que importa na Magna Carta, no entanto, é o fato de "a declaração reconhecer que os direitos próprios dos dois estamentos livres - a nobreza e o clero-existiam independentemente do consentimento do monarca, e não podiam, por conseguinte, ser modificados por ele" (p. 65).

Apesar da importância da Magna Carta, da Lei de Habeas Corpus, de 1679, e do Bill of Rights, de 1689, especialmente para a construção do constitucionalismo liberal, em face da separação de poderes e da centralização da função legislativa no parlamento, o reconhecimento dos direitos em seu sentido moderno somente aparecerá com as revoluções americana e francesa, como salienta Fábio Comparato.

As declarações de direitos americanas e francesas, que são fruto do Iluminismo, reagem à desigualdade inerente à sociedade estamental. "Em pouco tempo, aliás, per- cebeu-se que o espírito da Revolução Francesa era [sobretudo] a supressão das desigualdades" (p. 118). A partir de Locke, e especialmente Rousseau, o homem racional, emancipado, igual e livre para decidir seu próprio destino, passa a ser o parâmetro de todas as coisas. Ao redigir a Declaração de Direitos de Virgínia, de 1776, logo após a ruptura dos laços com a metrópole, Jefferson acolhe a argumentação dos jusnaturalistas ao afirmar que "todos os homens são por natureza igualmente livres e independentes e têm certos direitos inatos de que, quando entram no estado de sociedade, não podem, por nenhuma forma, privar ou despojar a sua posteridade, nomeadamente o gozo da vida e da liberdade, com os meios de adquirir e possuir a propriedade e procurar e obter felicidade e segurança" (p. 101). Da mesma forma os franceses, ao redigirem a Declaração dos Direitos do Homem e do Cidadão, de 1789. estabeleceram que todos "os homens nascem e são livres e iguais" e que o fim de toda a "associação política é a conservação dos direitos naturais e imprescritíveis do homem" (p. 138), numa clara sintonia com a idéia de direitos como fruto da razão, declarada por intermédio da lei, expressão da vontade geral rousseauniana.

O Estado e os direitos são, assim, obras humanas que têm por finalidade última a preservação da esfera de dignidade das pessoas. Apesar de Jefferson se utilizar da idéia de direitos inatos, que se encontram em estado de natureza, trata-se de uma utilização retórica, que esconde uma construção ética. Evidente que os homens não são iguais, como afirmado por Jefferson, do ponto de vista de sua riqueza, poder, complexão física, inteligência, etc., mas sim do ponto de vista moral. Como destaca Habermas, mais de dois séculos depois, os direitos básicos não são uma dádiva transcendente, mas uma conseqüência da decisão recíproca dos cidadãos iguais e livres de "legitimamente regular suas vidas em comum por intermédio do direito positivo" (3). O contrato social é apenas uma metáfora dessa decisão, assim como os momentos constituintes, em que se declaram direi-
3 Jurgen Habermas, Between Facts and Norms, Cambridge MIT Press, 1996, p. 119 
tos, são tentativas de dar concretude aos ideais de autonomia e do livre estabelecimento dos princípios de justiça e das leis sob as quais a comunidade pretende viver.

As declarações liberais, entretanto, como nos lembra Fábio Comparato, não enfrentam a questão da desigualdade material. A abstração e formalidade com que foram concebidas limita o seu potencial transformador. Este será o ponto básico da crítica de Marx, ao fazer uma análise da Declaração Francesa, em sua obra A Ques tão Judaica (p. 171). Ao garantir direitos que separam a esfera pública da privada, a Declaração estaria apenas mantendo uma situação de natureza dentro da nova esfera privada, assegurada pelo Estado, que deve preservá-la, sem intervir. A esfera cercada por direitos burgueses tem por função básica garantir o mercado, que nada mais é do que uma extensão do estado de natureza, onde deve prevalecer o mais forte, aquele que tenha domínio sobre os meios de produção. Ao vender a sua força de trabalho, ou seja, ao realizar um contrato que é protegido pela Declaração de Direitos, como parte intrínseca do direito de propriedade, as pessoas estão indiretamente alienando também seus demais direitos. "O direito humano à propriedade privada, portanto, é o direito de desfrutar o seu patrimônio e dele dispor arbitrariamente, sem atender aos demais homens, independentemente da sociedade... [sendo] a segurança o conceito social supremo da sociedade burguesa" (4) como meio de preservação da sociedade.

$\mathrm{O}$ que Marx não previa é que com a criação de uma esfera de liberdade individual, associada à participação da população no processo político, especialmente da população mais carente, articulada pelos partidos de orientação socialista, as cartas de direitos passariam por um processo de transformação. Como demonstra Fábio Comparato, pelos exemplos da Constituição mexicana, de 1917, e da Constituição de Weimar, de 1919, as demandas de caráter social passam a ser também incorporadas como direitos frente ao Estado.

Os totalitarismos e autoritarismos que assolaram os diversos continentes na pri- meira metade do século XX provocaram uma ruptura com essa lógica dos direitos humanos que vinha sendo paulatinamente construída no decorrer de séculos (5). O holocausto e as outras barbáries do período, como os campos soviéticos de trabalhos forçados e mesmo a bomba atômica, causaram um profundo choque na consciência da comunidade internacional. Écomo reação a essa demonstração de irracionalidade e da capacidade do homem de se autodestruir que surge a idéia contemporânea de direitos humanos. Trata-se de uma reação, ainda que filosoficamente não bem resolvida, ao vazio ético deixado pelo desencantamento que favoreceu o nazismo e todas as atrocidades do período.

Assim, Fábio Comparato nos apresenta a nova fase dos direitos humanos, que se inaugura com a formação das Nações Unidas e a adoção da Declaração Universal dos Direitos Humanos, que teve por objetivo estabelecer um novo horizonte ético, a partir do qual a relação dos Estados com seus cidadãos pudesse ser julgada por um paradigma externo ao próprio direito de Estado. A Declaração, como nos lembra o autor, "é uma recomendação" (p. 209) que foi feita pela Assembléia Geral das Nações Unidas. Não sendo um tratado, não pôde ser ratificada e, portanto, não tinha originalmente pretensão de obrigar os Estados juridicamente. O que dá a dimensão das dificuldades políticas de se aceitar esse paradigma moral como direito. Como destaca o autor, no entanto, poucos hoje negam o seu valor jurídico, inclusive como direito internacional costumeiro.

De qualquer maneira a Declaração passou a ocupar um papel tão importante no imaginário da comunidade internacional após a Segunda Guerra Mundial, servindo de respaldo ideológico no processo de descolonização, assim como na luta de resistência contra os regimes autoritários, nas mais diversas partes do mundo. Nesse mesmo lanço passou a ser incorporada pelos Estados, como direito em suas constituições (6). Talvez a Constituição brasileira de 1988 seja exemplar nesse aspecto, não apenas pela incorporação da lógica da De- 
claração e dos demais instrumentos internacionais de proteção da pessoa humana, mas também pela ampliação e atualização de seus ideais. A nossa Constituição é generosa e criativa em termos da confecção dos princípios de justiça segundo os quais a sociedade deve se organizar. Além de uma pormenorizada carta de direitos, por força do parágrafo $2^{\circ}$ do artigo $5^{\circ}$, abre suas portas para que uma série de direitos decorrentes do regime e dos princípios por ela adotados e dos tratados internacionais dos quais o Brasil seja parte passem a ingressar em nosso ordenamento numa posição privilegiada.

O sistema global de proteção aos direitos humanos só passou a ter mais consistência, no entanto, com a adoção da Convenção Internacional de Direitos Econômicos, Sociais e Culturais e a Convenção Internacional de Direitos Civis e Políticos, ambas de 1966. A conjunção desses documentos forma o International Bill of Rights, cerne do processo global de constitucionalização.

Com conteúdos distintos, nos ensina Fábio Comparato, a primeira Convenção incorpora aqueles direitos que decorrem da tradição socialista, estabelecendo obrigações positivas aos Estados. Seu grande defeito, semelhante a muitas constituições nacionais, foi dar caráter programático ou progressivo a esses direitos, o que não escapa à crítica do nosso autor (7). A Convenção de Direitos Civis e Políticos, por sua vez, abriga direitos decorrentes do movimento liberal e democrático, já reconhecidos pelos constitucionalismos nacionais desde o século XIX, dando-lhes eficácia imediata. Criou este tratado um Comitê de Direitos Humanos, que, entre outras funções, analisa relatórios preparados pelos Estados, assim como denúncias individuais de violação dos direitos estabelecidos pela Convenção (8).

Diversas outras convenções foram adotadas pelas Nações Unidas nestes últimos cinqüenta anos. Cada uma delas voltada a tutelar direitos específicos ou grupos determinados de pessoas. Trazem também mecanismos próprios de fiscalização e monitoramento. O sistema da ONU, no entanto, padece de grande fragilidade, posto que a própria Carta das Nações Unidas determina que a Organização seja ciosa com a esfera de soberania dos Estados, tal como reconhecido pelo artigo $2^{\circ}$ da Carta.

Fábio Comparato, embora lendo criticamente a atuação das Nações Unidas, apresenta-nos progressos relevantes, ocorridos nos últimos anos, especialmente a partir da Conferência Mundial de Direitos Humanos realizada em Viena, em 1993. Entre esses progressos destaca-se a criação de um Alto Comissariado para Direitos Humanos, que tem por função articular as ações das Nações Unidas nessa esfera, e do Tribunal Internacional Criminal Permanente, a partir das experiências dos Tribunais de Ruanda e da Ex-Iugoslávia. Dessa forma o sistema global, que até 1998 não contava senão com parâmetros normativos e agências fiscalizadoras (comitês e comissões), passou a poder também contar com uma instância jurisdicional, ainda que em moldes bastante distintos daqueles existentes nos sistemas regionais de direitos humanos (9). Ao menos para o crime de genocídio, os crimes contra a humanidade e os crimes de guerra, o sistema das Nações Unidas se fortaleceu neste último ano.

Pela leitura d' A Afirmação Histórica dos Direitos Humanos, podemos depreender que os sistemas regionais europeu e interamericano são mais bem estruturados e tecnicamente mais viáveis, aproximando-se de um regime internacional de caráter constitucional. O que permite um certo otimismo. Esses dois sistemas regionais são fundados a partir de tratados internacionais, que não apenas dão o parâmetro normativo, criam sistemas de monitoramento, mas também estabelecem instâncias jurisdicionais de proteção dos direitos humanos, que se encontram em pleno funcionamento.

No continente americano o sistema passou a se desenvolver a partir da adoção, pela Organização dos Estados Americanos, da Declaração dos Direitos e Deveres do Homem, em 1948. Em 1959, sob os auspícios da OEA e dentro de sua estrutura constitucional, foi criada a Comissão

\footnotetext{
7 Art. 2 (Cidesc/ 1966). Cada Estado parte na presente Convenção compromete-se a adotar medidas... que visem assegurar progressivamente. o pleno exercício dos direitos reconhecidos no presente Pac to..."

8 Isso quando o Estado expres samente acatar a jurisdição do Comitê, por intermédio do Protocolo Adicional à Convenção.

9 Para uma precisa análise ver: José Francisco Sieber Luz Filho, "Perspectivas para a Corte Internacional Permanente" in Revista do llanud, n. 12, São Paulo, 1998
} 
Interamericana, com a função primordial de implementar os direitos humanos no continente. Somente em 1969 é que surgiu a Convenção Americana de Direitos $\mathrm{Hu}$ manos, com força jurídica de tratado internacional (pp. 332 e segs.). Esta Convenção, que só entrou em vigor em 1978, reconheceu direitos de ordem civil, política e social, estes últimos apenas de forma "progressiva" (10).

A Convenção também estabeleceu uma Corte Interamericana de Direitos Humanos e deu um novo status à Comissão, que passou a funcionar como órgão da Carta da OEA e órgão da Convenção, para aqueles países que desta se tornassem parte. As competências comuns da Comissão, tanto como órgão da Carta como da Convenção, são bastante genéricas. Nos anos 70 isso permitiu que a Comissão de forma bastante criativa desempenhasse um papel tremendamente importante na denúncia das violações que eram cometidas pelos regimes militares então no poder. Já sob o mandato da Convenção, a Comissão passou a ter funções mais concretas, como receber denúncias individuais, representá-las junto à Corte Interamericana (11), fazer investigações no local, ou solicitar informações dos governos (12).

A Corte Interamericana de Direitos Humanos é um autêntico tribunal, que pode exercer, para aqueles Estados-parte que reconheçam sua jurisdição, uma prestação jurisdicional de caráter contencioso, relativa a todos os casos concernentes à interpretação e aplicação da Convenção Americana, ou outros tratados de proteção à pessoa humana, na esfera da comunidade interamericana. A Corte só poderá ser provocada em sua jurisdição contenciosa pela Comissão ou pelos Estados-parte que aceitem a sua jurisdição. Suas decisões podem fazer cessar uma situação de lesão aos direitos protegidos pela Convenção, como tortura, prisão ilegal, ou mesmo buscar a suspensão de uma norma que viole os dispositivos da Convenção, exercendo, assim, uma espécie de judicial review dos ordenamentos jurídicos domésticos em face da Convenção. Isso pode ser feito ainda de forma pre- ventiva, através da jurisdição não contenciosa da Corte (13). Por outro lado a Corte também pode determinar que os Estados indenizem as vítimas ou os seus familiares. O que ocorreu pela primeira vez no caso Velasquez, em que o governo de Honduras, responsável pelo seu desaparecimento, foi condenado ao pagamento de uma indenização à família (14). Nesse aspecto ocorre um dos pontos de maior proximidade entre o sistema interamericano e os sistemas domésticos. De acordo com o artigo 68 da Convenção, “a parte da sentença que determinar a indenização compensatória poderá ser executada no país respectivo pelo processo interno vigente para a execução de sentenças contra o Estado". Assim, a decisão da Corte não tem força de sentença estrangeira, mas de uma sentença judicial como outra qualquer, numa perfeita integração com os sistemas domésticos.

Estaé parte da história contada por Fábio Konder Comparato em A Afirmação Histórica dos Direitos Humanos. Como o próprio autor sugere

“o que se conta, nestas páginas, é a parte mais bela e importante de toda a história: a revelação de que todos os seres humanos, apesar das inúmeras diferenças biológicas e culturais que os distinguem entre si, merecem igual respeito, como únicos entes no mundo capazes de amar, descobrir a verdade e criar a beleza. É o reconhecimento universal de que, em razão dessa radical igualdade, ninguém - nenhum indivíduo, gênero, etnia, classe social, grupo religioso ou nação - pode afirmar-se superior aos demais" (p. 1).

Trata-se, assim, de um livro sobre os direitos humanos, como uma das maiores invenções da humanidade, pelos quais mulheres e homens buscaram conter seus instintos de violência, por força de seus instintos de vida, capacidade de agir eticamente, capacidade de amar.

O livro de Fábio Comparato não constitui, no entanto, apenas uma enorme empreitada teórica. Temos, antes de tudo, um 
livro voltado a educar e conscientizar sobre valor e a dimensão ética de cada ser humano, portanto um livro voltado à construção de um mundo mais justo. Nunca devemos esquecer que Fábio Comparatoé, sobretudo, um grande professor. Ainda que nas últimas páginas do texto nos defrontemos com um autor cético em relação ao futuro e suas ameaças aos direitos humanos, trata-se de uma obra que nos oferece o antídoto para tais ameaças. Como sugere o preâmbulo da Declaração dos Direitos do Homem e do Cidadão, de 1789, “a ignorância, o descuido ou o desprezo dos direitos humanos são as únicas causas das desgraças públicas e da corrupção dos governos". Após a leitura do livro de Fábio Comparato, é impossível desconhecer ou desprezar a força desse antídoto chamado direitos humanos.

Não poderia terminar esta resenha sem, no entanto, dizer algumas palavras sobre o autor. Isso sem qualquer intenção laudatória, até porque causaria um profundo desconforto ao nosso professor. Mas, na medida em que a ação de Fábio Konder Comparato jamais esteve apartada de sua reflexão, é fundamental conhecê-la, para que se possa dar a devida interpretação à sua obra.

Como lembra Celso Antônio Bandeira de Mello, outro de nossos autênticos juristas, Fábio Comparato diferenciou-se desde os tempos do Colégio São Luiz por sua vasta cultura. Ainda que tenha dedicado parte de seus estudos e de sua vida profissional ao direito comercial, legando-nos um clássico, que é $O$ Poder de Controle nas Sociedades Anônimas, Fábio Konder Comparato tem sido sobretudo um jurista-filósofo, na verdadeira acepção da palavra, não apenas pelo seu total domínio das diversas áreas do direito e das humanidades, como pela sua intransigência ética e compromisso com a cidadania.

Membro da Comissão de Justiça e Paz, ao lado de José Carlos Dias, Margarda Genevois e tantos outros, sempre sob a liderança de D. Paulo Evaristo Arns, participou da resistência ao regime militar conjugando, desde então, a gramática radical dos direitos humanos. Restabelecida a democracia, não se acomodou na confortável posição de grande advogado comercialista: elaborou um anteprojeto de constituição, a pedido do Partido dos Trabalhadores, colaborou com Evandro Lins e Silva no processo de impeachment do ex-presidente Fernando Collor de Mello. Evandro Lins e Silva, aliás, a quem, ao lado de Sepúlveda Pertence, assessorou no Supremo Tribunal Federal, antes que o grande criminalista fosse cassado pelos militares.

Fábio Konder Comparato não tem sido, no entanto, um homem público eventual. Nas últimas duas décadas tem participado ativa e incansavelmente do debate sobre a democracia, o estado de direito, a ética na política, o funcionamento das instituições responsáveis pela aplicação da lei, a desigualdade, em resumo: tudo o que é relevante no Brasil.

Ao lado de Maria Vitória Benevides, criou a Escola de Governo, voltada à formação de líderes e agentes públicos compromissados com o Brasil e com o seu povo. Recentemente, com Dalmo Dallari, entre outros, organizou o Centro de Direitos Humanos da Faculdade de Direito da Universidade de São Paulo, com um amplo engajamento de alunos. Na pós-graduação do Largo de São Francisco vem formando uma nova geração de juristas, através de um rigoroso e inovador curso de Direitos Humanos.

Estas informações me parecem importantes, pois nos auxiliam a compreender o sentidoético de A Afirmação Histórica dos Direitos Humanos. Como a vida do seu autor, trata-se de uma obra ao mesmo tempo erudita e engajada. Detalhista quanto ao aspecto técnico dos documentos jurídicos analisados, jamais esquece o contex to histórico e filosófico em que foram produzidos e, principalmente, a finalidade para a qual foram instituídos. A Afirmação Histórica dos Direitos Humanos constitui uma autêntica provocação aos seus leitores para que se transformem em verdadeiros agentes dos direitos humanos, sem o que tratados e declarações não passam de meras promessas vazias. 